\title{
Interdisciplinary Practice: Dialogue as Action to Resist Colonialism in Higher Education
}

\author{
Alison J. Sammel1 ${ }^{1}$ Marcus Waters ${ }^{2}$ \\ ${ }^{1}$ Education and Professional Studies, Griffith University, Gold Coast, Australia \\ ${ }^{2}$ School of Humanities, Griffith University, Gold Coast, Australia \\ Email: a.sammel@griffith.edu.au, marcus.waters@griffith.edu.au
}

Received 28 May 2014; revised 3 July 2014; accepted 12 July 2014

Copyright @ 2014 by authors and Scientific Research Publishing Inc.

This work is licensed under the Creative Commons Attribution International License (CC BY). http://creativecommons.org/licenses/by/4.0/

c) (7) Open Access

\section{Abstract}

Two colleagues, one who is identified as a Kamilaroi First Nation of Australia man, and a woman who is identified as Australian, from European decent, come together through dialogue to explore interdisciplinary practices within their university setting. Focusing on their areas of expertise, they share the similarities and differences associated with the concepts of identity, identifying and binaries between the teaching and learning of Science Education and First Nations Knowledge production. Through emerging dialogue, they realize that even though their cultural backgrounds are completely different, both are subjected to the complexities of hegemonic binaries that impact and influence their teaching practice. In striving for equity, both authors aim to continually recognize and challenge the binaries that privilege some agendas and students, and marginalize others. By sharing assumptions, beliefs and practices, the article invites the possibility that something new can emerge from their encounter to generate innovative understandings that will inform future practice. Through their praxis and dialogues with students, both have come to understand that it is not only those students marginalized by the system that appreciate their actions, but those who are privileged also benefit as they become more aware of an ever changing world around them.

\section{Keywords}

Interdisciplinary Practice, First Nations Knowledge Production, Engaging Marginalized Students in Science Education, and Colonialism

\section{Gamiluyilaambiyal (Before the Beginning)}

Our peoples have left with us deep roots which have empowered us to endure the violence of oppression. They 
are the roots of survival but not constriction. They are the roots from which all growth is possible. They are the roots that protected our end from the beginning-Michael Dodson (1994).

Marcus: I, Dr. Marcus Waters identify as a member of the Kamilaroi First Nation of Australia before all else. What I have found unique within our epistemology compared to many other cultures around the world is the inherent principle of Gamiluyilaambiya... which in simple translation means a time before the beginning. The work of creationist theorist Rob Pope (2005) highlights that most cultures' theories of creation, from biblical to First Nations, have a Genesis, or starting point, "In the beginning..." as if to suggest our universe was created by a higher being from a void of nothing. This is not the case with Kamilaroi beliefs. Gamiluyilaambiya is a preamble to Genesis, a time before the start. It reflects our place within the world, and is constant, with no ending and no beginning, and connects us to the Universe and its creation for tens of thousands of years. The Kamilaroi shares this knowledge when sharing stories, as a multi generational dialogue. It is a form of pedagogy that passes knowledge from generation to generation through language, ceremony, art and dance. This pedagogy is interdisciplinary in its practice and reflects what Pope (2005) and David Maybury-Lewis (1992) refer to as highly advanced conceptual intellectual property. Teaching through dialogue interconnects Kamilaroi ways of knowing and understanding with ways of seeing the world. As Kamilaroi we believe that the universe has two aspects. There is the ordinary physical world in which we live and another connected world from which the physical world first originated. By keeping dialogue active and ongoing through multiple generations, people make links between the worlds possible. Through dialogue, understanding past events can evolve to create new insights for understanding the future. Engaging in dialogue is therefore very important to my people. How have you come to understand dialogue and its role in your culture Ali?

Ali: Growing up in part of Australia with little cultural diversity, I did not have to think about culture, privilege or identity. All the people I knew were similar to me: white and middle class. Without a recognition that being of European heritage or "white" implied being part of a culture, I understood words like "ethnicity" to be reserved for other people: people who did not look like me. The "luxury" of this ignorance meant I grew up assuming the rest of the world experience life the way I did. This understanding changed when I went to university to undertake my masters and was exposed to emancipatory forms of dialogue. Up to this point much of my education had been about the acquisition of content. I learnt facts, content knowledge and processes. However, at graduate school, questions and problems were posed that inspired critical reflection on the world for the purpose of understanding it more fully and then seeking to transform it. As such, I began to experience deep, applicable, life changing learning through dialogical encounters, and developed the mindset and skills to continue this style of learning with many different individuals in different circumstances. I have found that through dialogue, new understandings occur, understandings that can blend the new and old. I have also found that these new understandings result in new practices and ways of thinking.

The educative power of dialogue is not new in Western education: Plato, Dewey, Habamas, Gadamer, Freire, Burbules, etc. have all spoken of the benefits of dialogical education, each in their own way. To this end, Burbules (1993) states, "dialogue represents a continuous, developmental communicative interchange through which we stand to gain a fuller apprehension of the world, ourselves, and one another ...none of the participants knows exactly where the dialogue is headed" (pp. 8-9). Gadamer (1989) suggested that in dialogue conversation takes "its own twists and reaches its own conclusions" (p. 383). Fairfield (2010) contents that "all this shows that a conversation has a spirit of its own and that the language in which it is conducted bears its own truths within it” (p. 79). It is from this spirit of conversation that I gained a better understanding of myself, and my place within this world. My own teaching and learning practices are embedded with this educative inquiry that seeks not to lead students to a particular end point, but to develop the habits of mind that will continue their journey of reflection, research, inquiry and dialogue.

Ali and Marcus: Given our mutual belief in the power of dialogue to generate knowledge, we have decided to write this paper as a form of dialogue. By practicing the epistemology that forms part of our different identities, we discuss personal and professional experiences, assumptions and expectations that liberate and restrict our academic lives. Focusing on our own areas of expertise within a university setting, we share the similarities and differences associated with the concepts of identity, identifying and binaries between the teaching and learning of Science Education and First Nations Knowledge production. Our aim is to expand the dialogue between interdisciplinary practice and increase our understanding of each other. Further, the article invites the possibility that something new can emerge from our encounter and generate new understandings that will inform our future practice. 
What you are about to read is a transcript of conversation between two people from completely different worlds. To recognize the importance of both wor(l)ds, and to encourage them to stand proudly beside each other, the narrative voice within each heading of this article uses a requisition of traditional Kamilaroi Aboriginal language base as a viable alternative to standard academic text.

\section{Nhamaburra-li (The Beginning)}

Our dialogue demonstrates an ontology that acknowledges the current binary dynamics that impact our individual and collective identities. We start with our common understanding that all ways of understanding the world need to be present if we are to provide a holistic picture of human thought within the university context. Whether you are First Nation Australian or from European heritage, your peoples' quest for knowledge began a very long time ago. Whether we were looking into a petri dish, or looking at the stars, we all wanted to make sense of our place in the world. Whether we wrote ideas down or stared into the fire and told stories, we all communicated our knowledge.

The concept of "binary" is a strong theme in this article. We begin this theme by suggesting that binaries can be understood as something made of or based on two things or parts. While it is acknowledged that binaries are not automatically negative or marginalizing, within the socio-cultural and historic development of universities binaries have often led to one member of the pair being positioned as more legitimate, appropriate, powerful, knowledgeable than the other. This "other" is constructed as in deficit, weaker and different (Mander et al., 2011). This weaker framing of the "other" within university infrastructure and discourse is significant as universities have historically embodied spaces far bigger than themselves. Rather than just understanding the university as a place of education, we need to be clear that they are places thought to symbolize truth, knowledge, merit, achievement, trustworthiness, objectivity and normality (Fine et al., 2004). These representations bolster the power of the privileged member of this binary and constitute hierarchies that work to exclude, deprive and even silence the marginalized member. Inherent in this process is the requirement that the marginalized member adopt the privileged member's assumptions, ideologies, values and indeed, their culture as a way of becoming legitimate. Due to this, complex patterns of social constructions occur within universities. For a person to make sense of privileged collective narratives (or understanding of the world) such as those offered in university settings, an individual must in some way share those "common" narratives so they can interpret and transfer meaning in their own lives. Without this "common" narrative, those holding competing discourses may be excluded or rendered uncomfortable.

Both individual and collective identities are shaped by multiple and competing discourses encountered over long periods of time. There is no older living epistemology than that of the Australian First Nation culture. In the Australian university context, the collective narrative of Australian First Nation peoples can be identified as the marginalized member within the Western binary. This article does not intend to expand the debate about the differences and similarities between these two cultures but seizes an opportunity for understanding and becoming comfortable in both ways of knowing to establishing a collegial model of interdisciplinary practice.

\section{Burrrulaagaarayngiyanigaa-gi (The Dialogue We Share)}

Ali: I am a Science teacher educator at a large university, where I work across 3 campuses teaching Science concepts appropriate for a Kindergarten to year 7 curriculums. I usually have between 250 - 300 students in my Science Education course. I believe my expected role within this institution is to teach primary Science in a way that develops my students' basic understanding of Science concepts, and to model and teach effective pedagogical practices that will allow my student to promote scientific ways of thinking and working with their future students. The ultimate goal is to encourage scientific literacy within my student cohort, so they can do the same with their students. The contemporary, dominant understanding of scientific literacy implies understanding Science concepts accurately and being able to apply them. To build this literacy in Science, it is expected that student hold the "accurate" scientific understanding of the concept based upon centuries of Western Science.

The role of the Science teacher is to generate situations in which students investigate, explore, discuss or by any other means come to discover the correct and accurate understanding of Science for that concept. This role is based upon a few key foundational "truths". The first is that the current scientific ways of understanding the concept are accurate, and other ways of knowing the concept, outside of this particular understanding, are inaccurate, according to Science. Students come into my Science classes with their own understandings of concepts, 
and these prior understandings can be understood in a few ways. They can be considered misconceptions, where the students' prior knowledge is viewed as "a frequent nuisance, for they provide pupils with funny goggles that distort the teachers' message, and, being often rather stable, render the pupils' minds inhospitable to the new wisdom, which therefore fails to germinate" (Claxton, 1986: p. 123). This perspective implies that the students' own knowledge is simply wrong and has no value in and of itself. Another perspective views students' prior knowledge in a more positive light, acknowledging that the student's own beliefs and experiences have helped them to construct and use their ideas about the world around them. If their constructed knowledge is not the same as the Science knowledge, it is usually referred to as an alternative conception. It is important within this view for the teacher to listen to students' prior knowledge in order to understand the alternative conceptions they hold. Knowing what students believe, the teacher can generate discussions or activities to help them construct the new, accurate and "scientific" understanding of the concept.

Marcus: The idea of misconceptions and alternative conceptions seems to be a key one in contemporary Science Education. Is this an assimilationist way thinking endorsed by formal Science Education?

Ali: Absolutely. This goal of replacing other ways of knowing and constructing new, accurate Science knowledge of a phenomenon is supported by Australia's quintessential curriculum for Science Education: the Australian Curriculum (of) Science. This curriculum was developed by the Australian Curriculum, Assessment and Reporting Authority (ACARA). ACARA is the national body tasked with the development of the Science curricular to be implemented in primary and high schools across Australia. This curriculum suggests students are "to develop the scientific knowledge, understandings and skills to make informed decisions about local, national and global issues and to participate, if they so wish, in Science-related careers" (ACARA, n.d.: p. 3). All nonScience views of how things work are ignored by this curriculum. From my perspective, whether we call the knowledge students come into our Science classrooms misconceptions or alternative conceptions, the implied goal is to create experiences so the students can refine their ideas and be in line with the current, dominant understanding of Science. Why are we told this is important? So our students can make better sense of the way in which the world works and make more informed choices and decisions. Encouraging students to form, improve, and change their ideas in accordance with mainstream scientific views becomes the critical focus of contemporary Science Education. To be successful in Science Education, students must replace their prior ways of making sense of the concept with these newly taught scientific understandings. How does this agenda for Science Education relate to the expectations and roles associated with your teaching and learning practice?

Marcus: Well, the short answer is that it doesn't, in fact it couldn't be any further from the way I am expected to teach. I started teaching at the university just as the "School of Arts" merged into the "School of Humanities". Having come straight from writing a prime time Australian television series on a commercial network my role was to re-invent screenwriting courses to be more industry compatible. The courses I teach are based in current industry standards and explore aspects of journey and character with reference to a Western traditional three-act structure. The courses demonstrate how the techniques of creative writing work to engage/reach audiences through the refining of practical skills in the context of theoretical information, together with current creative practice. Throughout the course participants are encouraged to explore notions of storytelling and narrative as techniques in creative writing with a primary focus on the collaboration of the screenwriter as part of a key creative team in consultation with both the producer and director. I usually have between 100 - 150 students in these courses, some of who have never written creatively before. In finding a narrative, I draw upon each individual student's life experience before entering the classroom. There is no definitive right or wrong. Students must draw on their prior knowledge base, and honour what they have come to know. They need to draw on their past: put simply how can you write Romeo and Juliet if you never felt love and loss? Therefore, life experience is essential to creative writing practice. They write fiction, but what makes it believable is their ability to transfer emotion in such a way that engages the audience.

Ali: Honouring student knowledge and assumptions is a very different concept from traditional Science Education. As a Science educator, I am supposed to listen to the stories my students bring into the classroom, but only in order to correct their knowledge base. The position from which you start sounds more inclusive, how does this compare with your own First Nations background and ways of storytelling? In what ways does your own background inform the ways in which you work?

Marcus: I can't help but embed my own notions into the teaching of screenwriting. For me personally, I am very fortunate in that my understandings are based upon ongoing ceremony and practices that I have experienced as a Kamilaroi First Nation Australian. In having the opportunity to design courses, I draw upon my own 
custodial obligation as a First Nation Australian, and also my experiences in film and television. However, by engaging within the university, while being labeled as Indigenous, I have found that I experience the world from a position that Cowlishaw (2004) describes as no longer purely Indigenous or non-Indigenous. Perhaps this is why I find myself not involved in teaching Indigenous knowledge as it may be more difficult for students to understand that a First Nation Australian could be both successful in a commercial industry and still practice their customary obligations and cultural practices. Unlike with screenwriting where yes, I am Aboriginal, and talk openly about my life experience as an Indigenous or First Nation man, the students are there to learn the screenwriting skills that I have. I am not so sure this would be the case if teaching Indigenous Studies, due to the binary of the dominant white culture and my own culture.

This binary is also present within Australian screenwriting. The Australian Academy has profited from the exploitation of ethnographic representations of Aboriginal people. Early Australian film was produced by Baldwin Spencer (1860-1929), Chair of Biology at the University of Melbourne, Director of the National Museum of Victoria, and Special Commissioner for Aborigines. Spencer's cameraman filmed the traditional ceremonies of "the Arunta" in 1899 for the purposes of anthropological and scientific research (Tobing, 2007: p. 65). Spencer used this ethnographic footage for self-promotion, commercial entertainment and spectacle.

Although museum expeditions almost always brought along cameramen proficient in photography and film, the actual use of film for research was rare. Far more often the footage was used for public entertainment... cinema, intended for scientific research purposes, was instead used for public spectacle, as a sensational means for attracting viewers and thus profit. The boundaries between the cinema of Science (cinematographe) and the cinema of entertainment (cinematoscope) were never clearly drawn (Tobing, 2007: p. 65).

More recently Australian cinema has improved its relationship with Aboriginal people with films such as "Samson and Delilah” (2009) and more recently "The Sapphires” (2012). Both films received both critical and commercial success.

Ali: Can you expand on this binary as you see it? And do you think this binary is changing in any way with more Aboriginal and Torres Strait Islanders participation in Australian universities?

Marcus: Yes, but the concern here is that in developing a First Nation Australian identity based in the urban experience we are giving up too much in assimilating to the needs of the university. What place is there within universities for traditional First Nations experiences and histories of the time prior to colonization? As uncles, aunties, fathers, mothers and ceremony leaders we talk about our identity as dialogue related to traditional ceremony, practice and ongoing cultural maintenance. But as academics and professionals, the majority of our time is spent discussing the ongoing effects of white culture and genocide, the lack of housing, health and employment issues. In these discussions, we are talking as if our cultures were only 200 years old, we seem to be dismissing sixty thousand years of pre-colonial history. It is not surprising, then, that we are beginning to lose connection with who and what we are as we now, as we debate among ourselves (and within ourselves) the true meaning of our unique First Nation Australian identity. This serves to alienate First Nations people (past, present and potentially future) who have somehow retained traditional knowledge outside of the binary relationship of intellectual resistance and colonization (O’Regan, 1999).

Ali: It's as if we are still seeing the effects of an old divide and conquer strategy being played out.

Marcus: Exactly, for First Nation Australian knowledge production to flourish within the academy we need to acknowledge the parallel traditional knowledge of those First Nation People who still speak and practice their culture prior to colonization. In doing so, I suggest that we encourage questions about the operations of culture, Science and art that crisscross First Nation Australian and non-First Nations academies of learning rather the politics in surviving colonization that is currently hijacking this most valuable intellectual property. I understand that boundary construction, though an important stage in First Nation Australian intellectual development (Nakata, 2008), and a necessary stage in the deconstructive project (Moreton-Robinson, 2009), can also arguably contribute to an ongoing act of colonization. It's hard to imagine things beyond this binary relationship. That has been my experience, but what are your thoughts and experiences with binary relationships and education?

Ali: Binary relationships in my experience relate to problematic interactions between capitalism, Science and education, all of which privilege Western knowledge over Aboriginal and Torres Straits Islander knowledge. These relationships lead to problematic Science classrooms where realities of privilege, power and knowledge play out in terms of what knowledge is taught and valued (those that favour dominant and economic agendas), the purpose of Science Education (based around profitability rather than social or environmental justice) and how Science is taught (the assimilation of one knowledge base over others) (Sammel, 2009). My involvement 
with these relationships has been to deconstruct how the social practice of Science Education is organized, and to analyze the economic, cultural, social and political forces that influence it. It becomes apparent in this analysis that Science equates to progress, namely economic progress (Calabrese Barton, 2001). This understanding is more overt than subtle. At the start of August 2013, Australia's Chief Scientist released a position paper about STEM (Science, Technology, Engineering and Mathematics) education in Australia. This report stated,

“Australia's productivity and competitiveness is under immense pressure. A key way to meet the emerging challenge of developing an economy for the 21st century is to grow our national skills base particularly the Science, Technology, Engineering and Mathematics (STEM) skills of our school leavers. Our relative decline of STEM skills are holding back our national economy and causing real frustration for employers" (Office of the Chief Scientist, 2013: p. 10).

This direction for Science Education concerns me because it does not consider the Gamiluyilaambiyal of the all students, from all cultures: their backgrounds, assumptions, agendas and goals. Science Education is not seen as "serving" the students and their community. The agenda of current conceptions of Science Education is to "educate" with the unspoken intention of bringing all students "up" to Science's "rigorous" standards of working and thinking.

Marcus: That's interesting and makes a lot of sense considering the devaluing of Traditional Indigenous knowledges (Paradies, 2006). Do you see any potential for Science Education to listen to the voices and experiences of students at all?

Ali: Yes, there is: but there's a catch. Science Education is inclusive of students' experiences, but it is the intentionality of the listening that is important. Science Education only takes into account the background knowledge of the students in order to make note of the flaws in their way of thinking and knowing, so the teacher can best assess the situation in order to redirect and promote scientific understanding. The western Science/Science Education agendas minimize or ignore First Nations epistemologies and aspirations, and seek to render both schools and students uniform or equivalent in their understanding of phenomena (McKinley, 1996). Science teaching fails to accept students' cultural understandings, especially if they depart from the precepts of current Science epistemology. This includes native languages and culturally appropriate learning strategies (Wood \& Lewthwaite, 2008). This lack of inclusions reflects the hegemonic agendas that assume scientific and technological breakthroughs and patents promote economic growth. There is no thought of investing in a Science Education that promotes cultural understanding and acceptance. The hegemony of current views of Science Education promotes only one way of understanding how the world works. By not valuing, teaching or including "other" ways of understanding the world and their technologies, Science Education fails to acknowledge the Gamiluyilaambiyal: the deep local knowledge, values, and beliefs of First Nations communities.

Marcus: As a Kamilaroi First Nation scholar, it is the hegemonic principals which frustrate me the most: you spend all your time having to explain yourself before ever getting to the point of the discussion-you are continually having to break down this notion of "other" just to be understood. It really does highjack true discussion. I can only assume there is some frustration for you also, not only in what you are being asked to teach, but how you are being asked to teach it?

Ali: I am uncomfortable with the dominant agenda of Science Education because of the simplistic and limited Science narratives offered to me as a Science teacher educator. These narratives do not address the complexity of teaching individuals who understand the world from within a repertoire of ideas different from the those contained in the Western, English language narrative. Students who make sense of the world from vantage points other than this Western perspective are marginalized as they bring particular images, storylines, metaphors and concepts from the cultures they been exposed. To be successful in Science courses, students are expected to undermine, or disregard the cultural ontology that they and their people have held for a long time and take up Science's ontology. Why Sciences' ontology is thought to be superior and taught at the expense of other ontologies is related to the long historical power interplay between binaries of Western Science and "other" ways of knowing and understanding the world. If Western ways of knowing are founded on the principals of economic success, then as Science educators, we really need to question what "success" is, and looks like, as the negative consequences of our actions are increasingly causing widespread social and environmental problems.

Marcus: Now, that hits on what really is the most foundational belief of all Indigenous concepts: as the Cree prophesy outlines, 
"When all the trees have been cut down, when all the animals have been hunted, when all the waters are polluted, when all the air is unsafe to breathe, only then will you discover you cannot eat money”.

Maintaining a balance with biodiversity is the very premise of First Nations belief systems. Unfortunately such understandings have become romanticized and are often not seen in practice anymore. The binaries created by the powerful relationships between capitalism, power and privilege have influenced all ontologies. Can you share with me some specifics about Science's ontology and the influence of this binary relationship?

Ali: In Science classrooms what is not often discussed, is that Science too represents an ontology. This ontology is expressed in models, images and metaphors. For example, there is no such thing as gravity. Gravity is a Science word, a metaphor, a concept used to explain a specific phenomenon. Scientific knowledge about this phenomenon is not static, but changing and evolving. So, if scientific knowledge about gravity changes, what is the "reality" of a phenomenon such as gravity? Another way of asking this question is: "Can the scientific understanding(s) of gravity be viewed as equivalent to reality?” Well, right now Science cannot definitively say so. Scientists will tell you that Science is self-correcting, so eventually we will be able to accurately understand, represent and model the reality of this phenomenon. However, in Science classrooms we expect students to relinquish their own ways of knowing phenomenon and "trust" in the processes and understandings of Science. To do this, students need to place a high degree of "faith" in the ontology of Science. To find this faith, students only have to reflect on the authority and power invested in the term 'Science' and how it is constructed and privileged by dominant groups within society.

Marcus: That's funny_reminds me of a yarn with my grandfather when I was a young fella... I was only 17 and Pop (my grandfather) walked into our kitchen and he could see that something was wrong, "Marcus... you look troubled, I think you need to take time off school,” he said. I explained to my grandfather that over the next couple of weeks I was to sit my senior exams - and that this was the most important time of my life.

“The most important time of your life?” Pop replied. "You're 17... you haven't even made love to a woman yet... held a child in your arms as it falls asleep or worked for a living... and the next few weeks are the most important few weeks of your life?” I had no idea of pedagogy, ontology or epistemology back then, only that Pop used to always go into these stories, or parables when he wanted to teach me something. I couldn't see then how narrative and storytelling related to ongoing cultural maintenance and meaningwhat I now understand to be a system of ontology where some stories resonate, but don't offer true meaning until one is much older-an Indigenous knowledge base that I now recognize is used as a rite of passage in becoming a young adult or gulumaldhaay. My grandfather patiently let me finish and then he continued. "It's like this, Marcus... the Whiteman forces you to think about so many things which just aren't that important... so much so that you forget what really is important!”

Now Pop didn't mean Whiteman as in all Whitemen, Pop was not a racist. The world has changed dramatically since I was 17, and back then it was pretty much just us (Aboriginal) and them (non-Aboriginal)... No, what Pop meant was that he was discussing the way most non-Indigenous peoples he had met throughout his life had acted, believed in a certain way... he wasn't labeling the whole entire race, just making observation... nothing more. Pop could see in my reaction that he wasn't getting through — I just wasn't getting it... That's when he said it, words of wisdom that I will remember for the rest of my life... "Understanding gravity doesn't make an apple taste any nicer... it still falls from the bloody tree...” I didn't know fully at the time what it was my Grandfather had just said to me... but I knew it was profound... Like I said, it's funny. Take away the romanticism and it's not that different, the power of Science to "discover" comes from a belief in certain processes: the scientific method. Is this where Science's authority for "knowing” phenomena and its authority to speak, comes from?

Ali: I believe so. Contemporary Science pedagogy teaches technical and process oriented scientific methods. This is a process that is understood to be unique to the scientific community and one that has the power to illuminate "reality". In teaching this process, the learner and the teacher are essentialized as logical, rational beings who can interpret the information unfolding before them and process it to reach the correct hypothesis. Depicted as devoid of emotions, fears, beliefs, cultural backgrounds, agendas, preferences and modes of pedagogical resistance, the step by step process of engaging with the scientific method is intended to validate faith in Science and helps students believe in the current scientific understanding of the investigated concept. This process offers the promise of increasing the student's overall efficiency and literacy in Science, and thereby offering the students an accurate understanding of the world. They can use this understanding to make more informed decisions 
and choices, choices that will lead to their economic success and that of the nation. This government endorsed and legitimated Science Education does not seek to explore how cultural understandings influence how the students engage with the information we "teach" them and offers little discussion on the effects that educating citizens in this way has on cultural identification or identify. Nor does it make room for other epistemological and economic ways of seeing the world.

In order to examine the complexity of the lived experience of teaching and learning in culturally diverse societies, Science Education needs to problematize its current simplistic and technical, cause and effect perspectives. We need to ask how the promises and assumptions of current Science Education teaching and curricula restrict our making sense of the way teachers and learners can and do experience and grow in Science Education. If we took the whole, embodied, feeling, thinking, socially constructed person into account, what would a conceptual change process look like in Science Education? As someone who teaches the next generation of Science teachers, these are the questions I have been wrestling with for the past 15 years.

Marcus: Such critical moments in reflection and understanding have been played out many times as strategic signposts of my own life. This understanding of lifelong learning as a journey of knowledge production before and after one becomes associated with a university appears to be missing within your description Science Education. In beginning our discussion we understood Gamiluyilaambiyal as strategic in that we don't fully appreciate the immediate world around us without reflecting on past events and future goals and aspirations. Analyzing dialogue as interdisciplinary through poetry and song within a First Nation Australian Dreaming, Pope (2005) states:

[T] his is not an activity which simply takes place regardless of humanity, in some free-standing time and space... "Through the singing we keep everything alive; through the songs the spirits keep us alive.” This is speech that acts and is acted upon: created, it creates in return. Such a view of creation as ceaseless recreation and of life itself being crucially dependent upon a mutually informing exchange of spirit and song, can seem strange and even unsettling to Western readers brought up in "the whiteman's way"... [T]he Aboriginal elder is very much a speaker-singer from and on behalf of the heart of his [sic] community (...) moreover, the complexly integrated wor(l)d [sic] of the poem plays havoc with hard-and-fast distinctions between story and history, fiction and fact; for the landscape recorded in and realised through this poem is both literal and metaphorical: a routinely recognisable "historical" time and place and a mythically conceived and invoked state of "the Dreaming". The latter, also called the "the Dreamtime", is "a time in the past whose values are still active in the present”. (Pope, 2005: p. 144)

To understand First Nation Australian pedagogy one must acknowledge a sublime connection that moves back and forth throughout human history, oblivious to time, place, culture and race. This is an epistemology ingrained within and through dialogue embedded within our need to express our identity from generation to generation. Life begins before you are born and continues after you die as you regenerate one common timeless narrative understood through ceremony.

Practically speaking there is no "creation from nothing". There is always something "before the beginning", just as there is always something “after the end”... (Pope, 2005: p. 37)

In order to link my beginning to my present, after years of enabling my own mob (people) through First Nation Australian participation and access programs, I needed to demonstrate to myself that I could implement our own (Kamilaroi) ways of teaching and learning within mainstream education courses. Traditional Aboriginal pedagogy is based in the inter-relatedness of all things and brings together "ways of knowing, ways of being, and ways of doing" (Martin, 2008). This is what I believe maintains our separation and uniqueness from nonFirst Nations approaches to Science, but what I find exciting is that you appear to be applying similar teaching strategies in your own classes.

\section{Biidjinma-li Yuwaba-y Bulaadjal-Araayngalingugiimub-li (Overcoming the Binary within our Practice)}

Marcus: I feel strongly that we cannot just dismiss the critical moments and lived experiences of each student as they enter the classroom. I integrate Gamiluyilaambiya (this time and life experience before the student enters my classroom) into my teaching as an integral resource in engaging student expectations and motivation. As a 
First Nation Australian man, I give myself permission to no longer be colonized. I apply my own First Nation teaching without the interference of binary relationships. My First Nation pedagogy not only breaks down the binary relationship between First Nation and Non-First Nations peoples, it allows demonstrated practice of First Nation knowledge systems to be successfully used within the university. This is done through the acknowledgement of a student's life-long learning, interdisciplinary practice and ongoing dialogue between teacher and student as interrelated and crucial to any partnership of learning.

In addition to First Nation pedagogy Western traditional and contemporary scriptwriting and creative writing practices are also encouraged within the curriculum, but only in such a way that it can best reflect lived experience and journey as essential elements to successful storytelling and dialogue. Peer feedback from Dr. Debra Beattie, Senior Lecturer and winner of the 2008 Individual Arts Education and Law University Excellence in Teaching Award 2009, supports the effectiveness of this approach.

Marcus and I co-taught "Writing for Performance" at the end of 2007 when the student evaluations were overall 6.8 out of 7. It was a high-water mark for me in terms of teaching in the university sector. Marcus' approach is inherently one founded on what he terms "Indigenous pedagogy". For me that meant that we could create a space for an intellectual exchange between students and teacher within the curriculum that was based upon a learning partnership. Each student had their personal journey to engage with over the semester, as well as the collective lived experience as each retelling of a story/journey became an important resource to draw upon (Debra Beattie, 2009).

Rob Pope (2005) also talks about this unique sense of interrelatedness; as opposed to the way non-First Nations or Western people have been taught to think:

...the distinction is an important one. Plato's image of the magnet suggests a one-way transmission of energy from a divine source through physical and human intermediaries to the audience. His is essentially a monologic, top-down model of the inspirational process. That of the Aboriginal elder is more dynamic and dialogic. It involves two- and many-way flows of energy, and, through them, kinds of reciprocal support and inter-animation. Clearly, then, a lot depends upon the precise process of inspiration; who or what is reckoned to be "breathing into" whom or what, through what means, and with what effects. (p. 92)

The key question is whether such First Nations epistemology can be nurtured into the future as First Nations scholars join the university and what was once unique in cultural practice becomes embedded in places outside of our own cultural space. We must take notice of, and position strategically, the traditional strength of the now isolated parallel tradition (the "other side" of the binary) and importantly, ensure it is not relegated to an inferior position.

Ali: So you are not only negotiating a binary within the university but also within your own First Nations approaches to teaching and learning. Can you describe this process and the First Nations pedagogies or methodologies you draw upon?

Marcus: The best way to describe this methodology would be as a culturally inclusive teaching practice based upon the engagement of students in a form of cultural and intellectual exchange. Teaching based in the interrelatedness of all things and brings together "ways of knowing, ways of being, and ways of doing” (Martin, 2008).

When my father was first taught the story of creation he was a young man, I mean 8 years old. That was the beginning of his initiation, see, and then he was taught that same story again at 12 . Then again at 18 and again at 30, that same story... it's a circular thing, in gaining knowledge. Each story take on new meaning, interpretation as you get older, there [are also physical] things you gotta do to, get painted up when you young fella and then [you] paint up nephews when you get older, that change [also] to when, that day you get to tell the yarn, you become teacher student and all that business... life was your teaching and learning this was "black fella" (Spearim, 2012).

In this way, teaching incorporates an epistemology that acknowledges each individual within the classroom whether First Nation Australian or non-First Nations as having the potential of contributing to a collective consciousness as a viable teaching resource. This resource, I believe, is currently untapped within the university's forms of teaching. How do you see the issue of interconnectedness and interdisciplinary approaches within Science Education?

Ali: The way I understand interconnectedness in Science Education is that Science itself is a social, cultural and political practice (O’Neill \& Calabrese Barton, 2005). If students are to feel part of school Science then the 
social, cultural and political must be included in classroom discussions. To highlight these interconnections, I believe that Science Education must discuss the ontology and epistemology of Science as well as the ways of thinking and working of Science. In my Science Education courses, to discuss what we know and how we have come to know it, I let Science understandings unfold as a story: an important, well researched and evolving story, but a story all the same. I present Science as a story for a few reasons. As professional teachers in Australia, professional standards dictate that teachers need to understand and teach Science content as described in curricular documents. I believe that to achieve this goal, my students, these soon to be teachers, need to deeply engage and understand scientific knowledge. Science is a powerful cultural story that one needs to know and to engage with in the Western cultures. All Western technologies are based upon Science and every job in the Western world can be understood through some aspect of this Science. Economic life relies on some form of Western technology. To resist, speak back to, or critique any aspects of Science in "academic" ways, a person needs to deeply understand what they are talking about and be able present informed arguments. Most importantly, I teach Science as a story as a way of exploring the interconnectedness you speak of, and to resist issues of power, privilege and marginality.

I present Science as one story among many that seek to explain phenomena. I encourage the exploration and understanding of the cultural, religious and other stories of my students. When we start exploring a concept, I ask my students to reflect on the stories they have been told or know about the concept in question. I ask them to take time to explore and engage with their stories, find out more about them, research, speak to the people who taught them, and then, where comfortable, discuss those stories online through discussion boards, in lectures and tutorials and in email to me. As a class, we listen to all the stories presented, including the Science story, and together we address questions that arise around issues of reliability, credibility, cultural capital and power.

Marcus: I completely agree with you that education should address questions around cultural capital and, like you, believe in the importance of this interconnectedness. It is important to improve mobility between Indigenous and non-Indigenous thinking. My priority as an Indigenous teacher in a mainstream classroom is to nurture a strong sense of independence in collective learning. This is best achieved by engaging students in mutually respectful discussions of their aspirations and expectation of the course. This is also to ensure that assessment criteria remain reasonable and yet challenging in relation to the expectations and goals set in partnership with each student. It is a methodology that uses contemporary academic and creative voices, research and storytelling as expressions of life experience in an active partnership between student and teacher. In telling and listening to what everyone is saying - do the students compare views and communicate seeing some as credible and legitimate and others not so in your classes?

Ali: Comparisons ultimately do occur, and students look to me to state which of the stories is the correct one. At this point we unpack the goals, purposes, expectations inherent in each story and develop an understanding that each story is a unique offering, and has a specific purpose. The students realize that learning Science is not about comparing stories to see which one is ultimately accurate. That is not an achievable end. It is about seeing that each story has a purpose and place in the person's life. My students understand that the stories we are told to help us make sense of the world are of varying importance to each storyteller, but each has a place in my Science course. As a cohort, we explore the benefits, limitations and feelings that emerge when all stories are "allowed" to just sit beside each other, without comparisons or judgments. As my students will encounter their own sets of stories in their future classrooms, I encourage them to seek to appreciate stories that are new to them, and understand them.

I understand there are long entrenched binaries and prejudices that will negate what I am trying to do. To judge the "other" is easier than to truly understand. But if understanding across cultures is to be achieved, then it needs to be taught, practiced, experienced and normalized.

Marcus: This to me is the key, to normalize diversity, to accept difference as integral in understanding the world. But I have found this hard to achieve, as the university does not appear to see pursuit of improving intercultural understandings and capital as a priority, but instead places priority on job security and placement-it's frightening. How do you specifically try and achieve acceptance and do you see evidence amongst radically different perspectives?

Ali: Throughout my Science courses I discuss how it would be arrogant of me to make assumptions, have expectations or judge people on the degree to which they believe in Science concepts that I am teaching. My role is to help promote a deep understanding of the Science story and all it includes, but I will not ask if my students believe the story or not. I make a very clear distinction between understanding and believing. What they actually 
believe about a phenomenon is their personal business and is reflective of a life-learning journey that started long before I met them, and will continue, I hope, long after they have left my classroom. My goal is for understanding, so as professional teachers in Australia, they can support the teaching and learning of Science. I will not ask them to give up any personal beliefs and assimilate themselves into the scientific understanding. In discussions, I explain that there are many aspects to Science that I deeply understand but have not integrated into my own personal belief systems. I understand the history, development, epistemology, ontology and contemporary viewpoints of Science, but I continue to hold and value my own beliefs about certain phenomenon. This does not threaten my professionalism or the depth to which I am passionate about teaching Science. I absolutely love teaching the fascinating stories of Science.

My process of teaching Science encourages students to see, understand and be respectful of the plethora of diverse knowledge systems surrounding them in the classroom in the knowledge systems of their peers. If Science teachers are to value the experiences and understandings of their students, rather than ignoring or providing superficial inclusion of some knowledge within selective sections of teaching, then teachers must become culture brokers (Aikenhead, 2001). The broker facilitates student movement between contemporary Science understandings and their cultural ways of knowing. To achieve this, the students' voices, languages and stories must be included alongside the stories of contemporary Science. For this to be successful, the teacher, or broker, must first negotiate the parameters of respectful dialogue and teach and maintain those parameters so students can feel safe within the classroom space. If inclusivity is valued within a classroom, this negotiation should be part of the foundation of any subject. Generating an open and respectful classroom environment underpins this cross-cultural approach to Science teaching.

\section{Ngamilma-li Winanga-y Bumala-y Bulaadjal (Students Reflect on Challenging the Binary)}

Ali: Each year my Science courses offer students the chance to formally evaluate the teaching and learning in my courses. Further, I also offer questionnaires and small group interviews after the course marks have been formalized and approved by the academic board. My students have the opportunity to speak or write comments without repercussions. Over the years, I have recorded the ways my Science students have understood, engaged with and internalized the Science they encountered in my course. The most common theme emerging from this data is that the students develop a greater appreciation and understanding of their own cultural stories to make sense of a phenomenon. Having to specifically think about what they believe, and about how they have come to believe certain things, and knowing their perspectives are valued, the students say they are more open to exploring the Science "voice" alongside their own. They also state they less likely to judge the different stories offered in the class. They state they understand that no matter where their knowledge comes from, whether from their cultural background or from Science, they are learning to be adaptive and apply the perspective best suited to help them to make sense of a situation, at that time. They describe feeling "liberated" to choose which knowledge base to use, knowing that for them, both are applicable in various situations.

Marcus: It must have been hard for your students in the past not to be able to acknowledge what they believe, but how wonderful that they now feel free to talk about what they believe in your class.

Ali: The vast majority of my students, particularly those who are Australian First Nation peoples, or those who strictly adhere to a religious base, tell me they feel "liberated" when engaging in Science Education this way, as they feel they are "given permissions" to hold different understandings about a phenomenon. They don't have to hide what they "believe". Exploring not only the scientific way of understanding the phenomenon, but more deeply searching their own cultural ways, they are finding spaces in which these knowledge stories come together and make sense to them. They see past the different titles and find connections where the stories are similar. They have suggested to me that both views do not have to be distinct entities.

The students have commented that in the past, they have disliked Science because they were repeatedly told that what they have come to know to be true is wrong and that they are somehow "lesser" beliefs than those whose beliefs match the current scientific explanation or those who solely believe in the Science story presented in class. They have suggested that they feel more comfortable in both understandings, letting both ways of understanding the world stand side by side. Students commonly say that they enjoy exploring Science through anthropological, philosophical, historical, sociological, political, cultural and environmental discussions, questions and debates. My students have found ways to move past the binary of understanding and accepting Science or understanding and accepting their cultural narratives. Even though for any individual there will be varying 
degrees of interaction between different ways of understanding the world around them, and although they will face varying degrees of internal and external conflict, many students are finding resolution in the idea that they can be knowledgeable and proud in more than one set of explanations. They describe realizing that this makes them culturally stronger.

Marcus: I understand what your students feel. The Australian university academy provides no formal consensus about what represents First Nation Australian epistemology as a working basis for applied pedagogy outside of strategies in surviving colonization (Dodson, 2003). That I am able to speak and write in my own language not only is a sign of my authority to negotiate successfully the binary of colonization as a First Nation Australian but also as a scholar introducing a notion of interconnection between two worlds. It is from within this space (a positive First Nation role-model that breaks the code of binary that sits over other Non-First Nations or student teacher relationships) that students are able to reflect and deconstruct a space that works best for their own academic experience. Student feedback states that in my courses students feel comfortable in taking control of their own academic journey. I simply guide this journey through traditional forms of scriptwriting as an educational pathway where individual student stories can be told. This allows me to negotiate the university environment as truly reflective of my ideas as both a black and white person, a "New Urban Dreaming". Like Paradies (2006: p. 358), I refuse to "surrender my other identities" in order to become accepted within an academy that is clearly subject to misinterpretation and institutional bias. Formal University Course Evaluations demonstrate students feel empowered as equal in a "partnership of Learning" as students share that my teaching allows their imagination to move beyond the binary, in an effort to suggest greater understandings, both rational and intuitive.

Ali: Does your practice reflect your experiences living in community, or your Gamiluyilaambiya?

Marcus: Yes, both. My teaching practice is framed in such a way to move First Nations scholarship away from academic critique and towards a provisional space which can document a parallel validity and authenticity for both the colonizer and the colonized—black and white, First Nation and non-First Nations.

... between demonstrating our capacity to engage the discourses of other disciplines (in order to make our case more easily understood), and actually distorting the most powerful characteristics of our field... (Wissler, 1997: p. 88)

“... between the generative act that brings a work into existence and the receptive act that is a proper appreciation of that work” (Davies, 2004: p. 26)

While negotiating these boundaries, giving respect to difference and becoming inclusive in practice, we create a space for a reservoir of knowledge, which is currently "untapped" in academia.

As someone who a First Nation Australian, and a successful screenwriter, I refer to myself as being neither colonizer or colonized. Throughout my time teaching at university I have always remained in the top $10 \%$ of their internal course teaching evaluations. My research practice has demonstrated the potential of First Nations pedagogy embedded within university structures. The curriculum I developed has shown that knowledge can be transferred from industry into a classroom using First Nation knowledge production and methods. A student of mine states:

The fact that he is so accepting of different cultures, particularly because of his Aboriginal background, it makes it easier upon students whom have been brought up with a different culture. Being Greek has definitely posed some issues throughout my life, and Marcus has helped me express these feelings into my writing, whether referred to directly or indirectly. A teacher that doesn't just teach what needs to be taught, but a teacher that inspires and helps us to grow emotionally and educationally, which is beyond anything a curriculum can ever hope to achieve on its own. (A student evaluation)

My own personal vision is that ultimately in my own journey as a teacher I will be able to demonstrate a command of a First Nation Australian pedagogy based upon a learning partnership that can be embedded throughout the university.

\section{Warraan (Conclusion)}

Ali: I explored the complexities with teaching Science Education within the university setting, and highlighted the cultural binaries that I believe exist. I have also offered ways I have found to speak back to, or resist these binaries. By inviting my students to reflect on and understand more fully their cultural stories around the 
Science we are learning, allows for us, as a class, to investigate the complexity of knowledge production and sharing within a multicultural and postmodern society. I also believe that together as teacher and students, we must discuss and disrupt modern notions and hierarchies of knowledge where Science knowledge is placed above non-scientific forms of human knowledge. The existence of other valid forms of knowledge should be acknowledged in Science classrooms, especially First Nations knowledge which directly relates to thousands of years of collective knowledge about local areas.

I seek to move beyond simplistic binary assumptions of Science Education, where you believe and understand Western scientific knowledge, or you are thought to believe an inaccurate perspective. I believe this assimilation should not be acceptable in contemporary education, and it seems my students agree with me. My students suggest that they see the need for understanding and appreciating cultural stories to be part of the future of Science Education.

Marcus: In negotiating the binary existent within the university setting associated to First Nation Australian knowledge production, I find myself returning to a place "before the beginning" to find an answer. The Kamilaroi First Nation Australian principle of "Gamiluyilaambiya" allows multi generational dialogue as a form of pedagogy that through language, ceremony, art and dance is interdisciplinary in its approach. Teaching through dialogue interconnects ways of knowing, ways of understanding and ways of seeing the world. By keeping dialogue active in building partnerships of learning between both teacher and student we acknowledge past events as critical moments that create new insights for understanding the future. This seeks to create a collegiate model of intellectual exchange and partnership between student and teacher. In this way the educator actively promotes self-confidence and belief in each student, their culture, and life experience. Teaching then allows marginalized groups a voice... a voice that not only acknowledges, but celebrates, diversity within the classroom and reflects upon life experience as essential in the way we teach and see the world.

Ali and Marcus: As we both come together and reflect on our conclusion, we realize that even though our cultural backgrounds are completely different, we are confronted with many of the same issues in our field of teaching. We are both subjected to the complexities of hegemonic binary that impact and influence our teaching practice. Through dialogue, we now have a deeper appreciation that it does not matter what your cultural background is: whether you teach Science or screenwriting, the university system seeks to lock people into established binary patterns. In striving for equity, we both aim to continually recognize and challenge the binaries that privilege some and marginalizing others. By sharing our assumptions, beliefs and practices we both feel more supported in our endeavours and recognize the continued importance of this agenda. Through our praxis, and in dialogue with our students, we have both come to understand that it is not only those marginalized by the system that appreciate our actions, but those who are privileged also benefit as they become more aware of an ever changing world around them.

\section{References}

Aikenhead, G. (2001). Students’ Ease in Crossing Cultural Borders into School Science. Science Education, 85, $180-188$. http://dx.doi.org/10.1002/1098-237X(200103)85:2<180::AID-SCE50>3.0.CO;2-1

Australian Curriculum, Assessment and Reporting Authority (n.d.). The Australian Curriculum: Science. http://www.australiancurriculum.edu.au/Science/Rationale

Beattie, G. (2010). Celebrating Teaching Seminar Series 2010: Griffith's University's seven Principles to Promote Excellence in Learning and Teaching Practices. Logan: Griffith University.

Burbules, N. (1993). Dialogue in Teaching: Theory and practice. New York: Teacher's College Press.

Calabrese Barton, A. (2001). Capitalism, Critical Pedagogy, and Urban Science Education: An Interview with Peter McLaren. Journal of research in Science Teaching, 38, 847-859. http://dx.doi.org/10.1002/tea.1035

Claxton, G. (1986). The Alternative Conceivers’ Conceptions. Studies in Science Education, 13, 123-130. http://dx.doi.org/10.1080/03057268608559934

Cowlishaw, G. (2004). Blackfellas, Whitefellas and the Hidden Injuries of Race. Melbourne: Blackwell.

Davies, D. (2004). Art as Performance. Oxford: Blackwell. http://dx.doi.org/10.1002/9780470774922

Dodson, M. (1994). The End In The Beginning: Re(de)finding Aboriginality. The Wentworth Lecture, The Australian Institute of Aboriginal and Torres Strait Islander Studies. http://www.aiatsis.gov.au/events/wentworth/docs/m0008523_a.pdf

Dodson, M. (2003). The End in The Beginning: Re(de)finding Aboriginality. In M. Grossman (Ed.), Blacklines: Contempo- 
rary Critical Writing by Indigenous Australians (pp. 25-42). Carlton: Melbourne University Press.

Fairfield, P. (2010). Education, Dialogue and Hermeneutics. London: Continuum International Publishing.

Fine, M., Weis, L., Power Pruitt, L., \& Burns, A. (2004). Off White: Readings on Power, Privilege, and Resistance (2nd ed.). New York: Routlegde.

Gadamer, H. (1989). Truth and Method (2nd ed.) (Trans J. Weinsheimer and D. G. Marshall). New York: Continuum.

Mander, A., Danaher, P. A., Tyler, M. A., \& Midgley, W. (2011). Beyond Binaries in Education Research. Florence, KY: Routledge.

Martin, K. (2008). Aboriginal Worldview, Knowledge and Relatedness Theory: A Framework for Pedagogy and Praxis and the Teaching-Learning Interface with Aboriginal Students. AIATSIS Seminar Series, Canberra.

Maybury-Lewis, D. (1992). Millennium: Tribal Wisdom and the Modern World. New York: Viking Penguin.

McKinley, E. (1996). Towards an Indigenous Science Curriculum. Research in Science Education, 26, 155-167. http://dx.doi.org/10.1007/BF02356429

Moreton-Robinson, A. (2009). White Possession: The Legacy of Cook’s Choice. In R. Summo-O’Connell (Ed.), Imagined Australia: Reflections around the Reciprocal Constructions of Identity between Australia and Europe (pp. 27-42). Bern: Peter Lang.

Nakata, M. (2008). Moving on Indigenous Studies. Keynote Address, Indigenous Studies \& Indigenous Knowledges Conference. Hobart: University of Tasmania.

O’Neill, T., \& Calabrese Barton, A. (2005). Uncovering Student Ownership in Science Learning: The Making of a Student Created Mini-Documentary. School Science and Mathematics, 105, 292-302. http://dx.doi.org/10.1111/j.1949-8594.2005.tb18130.x

O’Regan, H. (1999). If It’s Good Enough for You It’s Good Enough for Me: The Hypocrisy of Assimilation. In J. Brown, \& P. Sant (Eds.), Indigeneity: Construction and Re/Presentation (pp. 193-208). New York: Nova Science.

Office of the Chief Scientist (2013). Science, Technology, Engineering and Mathematics in the National Interest: A Strategic Approach. Canberra: Australian Government.

Paradies, Y. C. (2006). Beyond Black and White: Essentialism, Hybridity and Indigeneity. Journal of Sociology, 42, 355-367. http://dx.doi.org/10.1177/1440783306069993

Pope, R. (2005). Creativity: Theory, History, Practice. New York: Routledge.

Sammel, A. (2009). Turning the Focus from "Other” to Science Education: Exploring the Invisibility of Whiteness. Cultural Studies of Science Education, 4, 649-656. http://dx.doi.org/10.1007/s11422-009-9184-7

Spearim, P. (2012). Interview with Paul Spearim. Logan: Griffith University.

Tobing, R. F. (2007). The Third Eye: Race, Cinema, and Ethnographic Spectacle. Durham, NC: Duke University Press.

Wissler, R. (1997). Artistic Practice and Research: Towards a Community of Judgment. Double Dialogues: The Arts and their Theoretical Paradigms Conference Proceedings (pp. 88-105). Melbourne: Theatreworks.

Wood, A., \& Lewthwaite, B. (2008). Māori Science Education in Aotearoa New Zealand He Puteawhakarawe: Aspirations and Realities. Cultural Studies of Science Education, 3, 625-662. http://dx.doi.org/10.1007/s11422-008-9089-x 
Scientific Research Publishing (SCIRP) is one of the largest Open Access journal publishers. It is currently publishing more than 200 open access, online, peer-reviewed journals covering a wide range of academic disciplines. SCIRP serves the worldwide academic communities and contributes to the progress and application of science with its publication.

Other selected journals from SCIRP are listed as below. Submit your manuscript to us via either submit@scirp.org or Online Submission Portal.
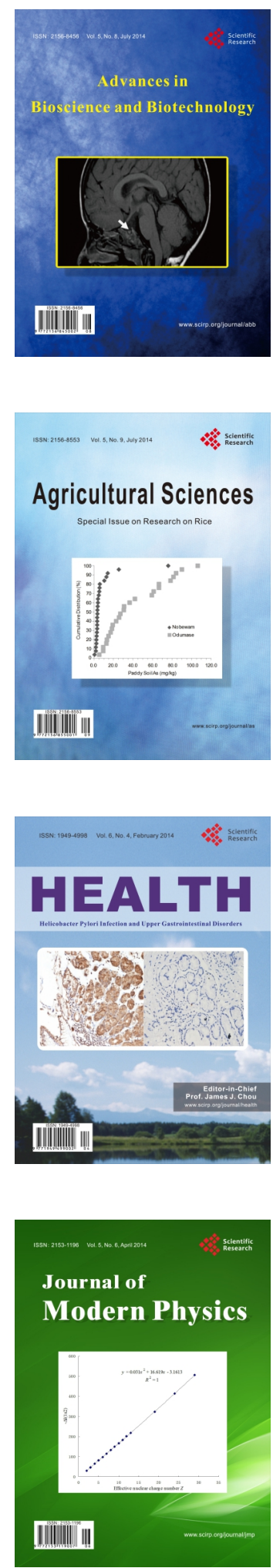
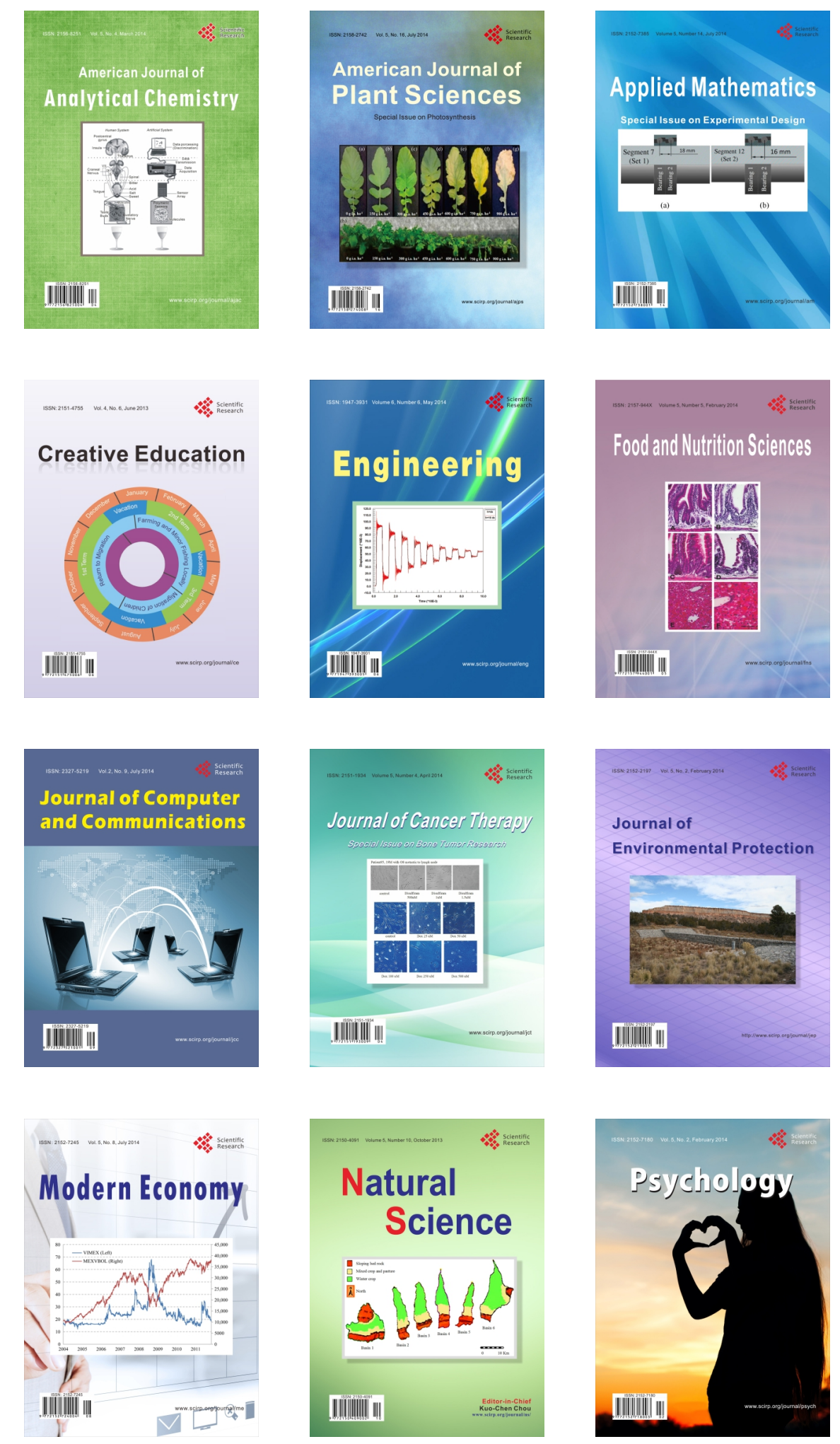